\title{
Flexibility as risk factor for stress-fracture development in South African male soldiers
}

\author{
PS Wood ${ }^{a *}$ and PE Krüger ${ }^{\mathrm{a}}$
}

\author{
${ }^{a}$ Department of Physiology, Division Biokinetics and Sport Science, University of Pretoria, Pretoria, South Africa \\ *Corresponding author, email:paola.wood@up.ac.za
}

\begin{abstract}
Background: Stress fractures are a common military training injury. Flexibility of muscles and joints may directly influence stress-fracture risk by way of altering the forces applied to bone. Hip external rotation and ankle plantar- and dorsiflexion have been inconsistently reported to pose a risk to stress fracture development in military soldiers. Thus this study aimed to present results that could help define the risk flexibility may pose in the development of stress fractures amongst military male soldiers. Methods: An experimental one-group pretest-posttest study design assessing the injury incidence, bilateral hip external rotation, ankle plantar- and dorsiflexion of South African male military soldiers $(n=100)$ undergoing 12 weeks of basic military training (BMT) was undertaken. The parametric $t$-test for dependent samples $(\alpha=0.05)$ and effect size (ES) was used to analyse the data.

Results: No stress fractures were diagnosed in the 100 operational military training injuries reported. BMT resulted in significant mean decreases of $10 \%(\mathrm{~L})$ and $17 \%(\mathrm{R})$ in hip external rotation and $18 \%(\mathrm{~L})$ and $14 \%(\mathrm{R})$ in ankle plantar flexion respectively, whilst a significant increase of $37 \%(\mathrm{~L})$ and $39 \%(\mathrm{R})$ dorsiflexion was observed.

Conclusions: Although normal ankle and limited hip external flexibility do not appear to predispose these male soldiers to stress fracture development these variables should not be excluded as possible intrinsic risk factors.
\end{abstract}

Keywords: ankle dorsiflexion, basic military training, flexibility, hip external rotation, risk factor, stress fracture

\section{Introduction}

Flexibility is defined as 'the ability to move a joint through its complete range of motion.' Flexibility of muscles and joints may directly influence stress-fracture risk by way of altering the forces applied to bone. Stress fractures are a common military training injury, with the first reported case being identified by Breithaupt in $1855^{2,3}$ and the incidence of sustained stress fractures in military soldiers reported to be as high as 31\%. ${ }^{4}$ Both intrinsic and extrinsic risk factors for the development of stress fractures have been investigated, predominantly in European and American soldiers. ${ }^{2,5-11}$ Numerous flexibility variables have been assessed as potential risk factors for the development of stress fractures in male soldiers. These have included a range of rear-foot inversioneversion, ankle plantarflexion-dorsiflexion, knee extensionflexion and hip rotation-extension, together with length of calf muscles, hamstring muscles, quadriceps muscles, hip adductor muscles and hip flexor muscles. ${ }^{2,5-9,12}$ From the numerous flexibility variables that have been assessed to determine the association between flexibility and stress fractures only range of hip external rotation ${ }^{7,9}$ and of ankle dorsiflexion ${ }^{12}$ have been associated, albeit inconsistently, with stress-fracture development. Soldiers with external rotation of the hip $>65^{\circ}$ and/or $<10^{\circ}$ ankle-joint dorsiflexion have been related to an increased risk of leg stress fractures. ${ }^{5,7,10,13}$ This study aimed to present results that could help define the risk flexibility may pose in the development of stress fractures amongst military male soldiers.

\section{Methods and materials \\ Participants and study design}

Ethical approval was obtained from both the South African National Defence Force (SANDF) ethics committee and the research ethics committee of the University of Pretoria to conduct the study. Both committees' ethical guidelines were followed throughout the study. The sample of convenience of
100 male participants (age $20.8 \pm 1.14$ years; body mass $59.5 \pm 8.79 \mathrm{~kg}$; stature $159.57 \pm 5.53 \mathrm{~cm}$; mean $\pm \mathrm{SD}$ ) were volunteers from the South African Health and Medical Service intake starting basic military training (BMT). The participants' characteristics are outlined in Table 1.

Of the cohort studied $99 \%$ were black whilst one participant was Caucasian. The fact that most of the participants were black Africans is important to note, as Caucasians appear to be at greater risk of developing stress fractures in both athletic and military cohorts than are other race groups. ${ }^{14-19}$ An experimental onegroup pretest-posttest study design was used..$^{20}$ No control group could be used, as all military soldiers who wish to be retained in military service need to successfully complete BMT, including the physical training (PT) component, in the allocated 12-week period. Failure to do so results in dismissal. After attending an information session during which the aim and study methodology were explained, participants were asked to read and sign an informed consent form. All participants had passed a medical entry examination carried out by a medical officer to ensure that they were free of any disorder that would contraindicate their attendance of BMT. A cycle menu, as prescribed by the SANDF, ${ }^{21}$ was followed by all participants during BMT, as three meals per day were provided to all soldiers for the BMT period.

\section{Measurements}

The range of motion (ROM) was assessed bilaterally for the hip and ankle joints, by the same practitioner, using a goniometer at the start and end of the 12-week BMT course. The hip external rotation was measured with participants in a sitting position. ${ }^{22}$ The goniometer was centred over the anterior part of the patella with the fixed arm positioned perpendicular to the floor and the moving arm placed over the anterior midline of the lower leg, using the crest of the tibia and a point midway between the 
Table 1: Participants characteristics in weeks 1 and 12

\begin{tabular}{|c|c|c|c|c|c|c|}
\hline & Pretest (mean \pm SD) & Posttest (mean \pm SD) & Mean difference & $95 \% \mathrm{Cl}$ of the difference & Effect size Cohen's D & $p$-value* \\
\hline Age (yrs) & $20.30 \pm 1.21$ & $20.62 \pm 1.21$ & -0.32 & & -0.26 & \\
\hline Mass (kg) & $61.78 \pm 6.89$ & $63.18 \pm 6.61$ & -1.40 & -2.36 & -0.21 & 0.005 \\
\hline Height (m) & $171.36 \pm 5.86$ & $171.36 \pm 5.86$ & 0.07 & -0.04 & 0.01 & 0.195 \\
\hline $\mathrm{BMI}^{+}$ & $21.43 \pm 2.16$ & $22.42 \pm 2.47$ & -1.00 & -1.66 & -0.43 & 0.003 \\
\hline
\end{tabular}

${ }^{*} p$-value compares the pretest and posttest in dependent sample $t$-test.

${ }^{\dagger} \mathrm{BMI}$ : body mass index.

malleoli for reference. The participant sat with knees flexed at $90^{\circ}$, with a rolled towel placed under the femur. The measurement was taken as the amount of rotation, in degrees, completed in external hip rotation with the distal end of the femur acting as the stabiliser. Participants were instructed not to rotate and laterally tilt the pelvis when executing the movement. ${ }^{23}$ Ankle ROM was measured with the participant in a sitting position. The goniometer was positioned over the most prominent aspect of the lateral malleolus with the stationary arm being the midline of the fibula, using the head of the fibula as reference. The moving arm was placed parallel to the lateral aspect of the fifth metatarsal, with the tibia and fibula providing the stabilisation. The participant sat on the end of the table with knees flexed and ankles positioned at $90^{\circ}$. The measurement was taken as the amount of rotation, in degrees, completed in dorsiflexion and in plantar flexion. ${ }^{23}$

\section{Injury incidence}

Injury incidence was monitored by the medical officer assigned to the military unit's sickbay for the duration of the training. A stress fracture was defined as'partial or complete fractures of bone that result from the repeated application of a stress less than that required to fracture bone in a single loading situation. ${ }^{\prime 2} \mathrm{~A}$ stress

Table 2: Time dedicated to each cardiovascular physical training (PT) programme component during the 12 -week basic training (BT) course

\begin{tabular}{lc}
\hline $\begin{array}{l}\text { Cardiovascular PT programme } \\
\text { component }\end{array}$ & $\begin{array}{c}\text { Time (minutes) allocated in 12- } \\
\text { week BT period }\end{array}$ \\
\hline Warm-up & 322 \\
Jogging & 950 \\
Interval training & 213 \\
\hline
\end{tabular}

fracture diagnosis was made when the Maquirriain and Ghisi25 diagnostic criteria had been met, which included no history of related trauma; pain associated with exercise and relieved by rest; localised bony tenderness, pain on bone loading or on paineliciting manoeuvres; and finally radiographic and magnetic resonance imaging (MRI) confirmation of diagnosis. All soldiers with suspected diagnosis of a stress fracture were evaluated with conventional radiographs and MRI. Stress fracture incidence was confirmed only if all four diagnostic criteria were met.

\section{Basic military training}

The participants followed a standardised BMT programme aimed at ensuring a combat-ready soldier at the end of the 12-week period. Standard military activities included drill, compliments and saluting, regimental aspects of procedures, general military aspects of conduct, mine awareness, musketry, shooting, map reading, signal training, field craft, water orientation, buddy aid, parade rehearsal and PT. The BT programme is difficult to quantify as it was made up of a variety of activities; however, the same standardised programme was followed by all the study participants. The cohort acted as its own control. A total of 48 periods of PT, each 40 min in duration, were completed by all participants in the BMT period..$^{26}$ A breakdown of time dedicated to the cardiovascular PT programme component during the 12-week BT course is provided in Table 2. The number of exercises completed for each muscle endurance physical training (PT) programme component is outlined in Table 3. Consistency and uniformity in the method of instruction was achieved by providing each PT instructor with the same detailed cyclic-progressive PT programme, together with a PT manual. The PT manual clearly explained all the exercises used in the PT programme. ${ }^{26} \mathrm{~A}$ sample PT programme for the third day of training is outlined in Table 4. The design of the PT programme accommodated the logistical limitations present in the BMT environment where large groups undergo the PT training simultaneously. The exercises had to be clear, completed within a small personal space and be easily corrected by the PT instructor. No individual training weights were available so all muscle endurance and strength exercises were designed based on resistance offered by own body weight and then progressed to the use of solid $20 \mathrm{~kg}$ timber wooden poles $(2.1 \mathrm{~m}$ in length by $25 \mathrm{~cm}$ in diameter) for exercises completed in pairs.

Table 3: Number of exercises completed for each muscle endurance physical training (PT) programme component during 12-week basic training (BT) course

\begin{tabular}{|c|c|c|}
\hline Muscle endurance PT programme component & No. of exercises completed in 12-week BT period & Resistance \\
\hline \multirow[t]{2}{*}{ Upper body muscle endurance exercises } & $28^{+}$ & $\mathrm{BW}^{*}$ \\
\hline & $64^{\ddagger}$ & $B W^{*}+W P^{* *}$ \\
\hline \multirow[t]{2}{*}{ Abdominal body muscle endurance exercises } & $28^{*}$ & $\mathrm{BW}^{*}$ \\
\hline & $64^{\ddagger}$ & $B W^{*}+W P^{* *}$ \\
\hline Lower body muscle endurance exercises & $28^{*}$ & $\mathrm{BW}^{*}$ \\
\hline
\end{tabular}

Notes: *BW: body weight.

**WP: $20 \mathrm{~kg}$ wooden poles.

${ }^{\dagger}$ Completed 3 sets of 10-12 repetitions of exercises performed by muscle groups in this body region in week 1 and then completed 2 sets of $10-12$ repetitions from week 2 progressing to 3 sets of 10-12 repetitions in weeks 3-4 of exercises performed by muscle groups in this body region.

${ }^{\ddagger}$ Completed all exercises with $20 \mathrm{~kg}$ wooden poles in pairs performed by muscle groups in this body region from week 5 to 12 starting with 2 sets of $10-12$ repetitions progressing to 3 sets of $10-15$ repetitions. 
Table 4: Physical training programme (day 3 of week 1)

\begin{tabular}{|c|c|c|c|c|}
\hline Serial no. & Exercise description & Exercise no. & No. of sets & Reps \\
\hline \multirow[t]{5}{*}{1} & \multirow[t]{5}{*}{ Warm-up } & Shoulder rolls-forward & 2 & 12 \\
\hline & & Shoulder rolls-backwards & 2 & 12 \\
\hline & & Jog gently around field & $3 \mathrm{~min}$ & \\
\hline & & Standing quadriceps stretch & 2 & $20 s$ \\
\hline & & Standing gastrocnemius stretch & 2 & $20 s$ \\
\hline 3 & Leg exercise & Lunges & 2 & $10-12$ \\
\hline 4 & Upper body exercise & Wide-arm push-ups & 2 & $10-12$ \\
\hline 5 & Abdominal exercise & Crunches & 2 & Max. \\
\hline 6 & Back exercise & Back extension on floor (opp. leg with opp. arm) & 2 & $10-12$ \\
\hline 7 & Leg exercise & Abduction straight leg raise & 2 & $10-12$ \\
\hline 9 & Cardiovascular activity & Walking/ Jogging & \multicolumn{2}{|c|}{$45 \mathrm{~s}$ walking $/ 15 \mathrm{~s}$ jogging $20=20 \mathrm{mir}$} \\
\hline 10 & Stretching exercise-upper body & Buddy pectoralis stretch & 3 & $20 \mathrm{~s}$ \\
\hline 12 & Stretching exercise-legs & Sitting hamstring stretch & 3 & $20 s$ \\
\hline 13 & Stretching exercise-legs & Achilles stretch & 3 & $20 s$ \\
\hline 14 & Stretching exercise-back & Lying back stretch & 3 & $20 s$ \\
\hline
\end{tabular}

Sufficient periods of recovery from weight-bearing stress during the early weeks of following the PT programme were achieved by including a $10 \%$ weekly progression in frequency and intensity in all exercises and building up from walking to jogging. ${ }^{23,27-33}$ All PT periods took place on grassed sport fields in military-issued trainers rather than combat boots. ${ }^{34,35}$ 'Pole PT' exercises were introduced from the fifth week. This was a cost-effective and viable method of resistance training based on the principle of free-weight training. ${ }^{23,33}$ Two isolated resistance exercises for each body region were performed at every PT session. Exercises were also varied so that the same exercises for a muscle group were not repeated on consecutive days and time was given for stretching at the end of each session. ${ }^{23,32}$

\section{Statistical analysis}

Data were analysed by means of the Statistical Product and Service Solutions package (SPSS 11.5 for Windows, SPSS Inc., Chicago, IL, USA). Descriptive statistics were calculated for all measurements. The Kolmogorov Smirnov test was used to assess normal distribution of the data. Owing to the normal distribution of the data, the parametric $t$-test for dependent samples was used to evaluate the influence of the BMT, using the conventional $5 \%$ level of significance. Effect size (ES) was calculated to assess practical significance with Cohen's ${ }^{36}$ criteria classifying effects as small $(0.2-0.3)$, moderate $(0.31-0.5)$ or large $(>0.5)$. The precision of these estimates was indicated by $95 \%$ confidence limits.

\section{Results}

The participants' characteristics at the start and end of the BMT period are outlined in Table 1. Significant differences in body mass and BMI were observed. Table 5 outlines the absolute mean differences in flexibility measures that were observed. The cohort had an initial mean hip external rotation and ankle plantar flexion of $25.57^{\circ}(\mathrm{L}) / 23.40^{\circ}(\mathrm{R})$ and $49.23^{\circ} \pm 8.35(\mathrm{~L}) / 45.67^{\circ} \pm 7.89(\mathrm{R})$ respectively, whilst the initial ankle dorsiflexion was $17.14^{\circ} \pm 3.65$ $(\mathrm{L}) / 18.25^{\circ} \pm 4.14(\mathrm{R})$ respectively. The $t$-tests for dependent samples showed a significant $37.4 \%(\mathrm{~L}) / 38.5 \%(\mathrm{R})$ increase in dorsiflexion and a significant $17.1 \%$ (L)/10.09\% (R) and $18.04 \%$ $(\mathrm{L}) / 14.43 \%(\mathrm{R})$ decrease in hip external rotation and ankle plantar flexion respectively.

Table 5: Absolute mean difference, 95\% confidence intervals (Cls) and effect size in flexibility scores (mean \pm SD) of the soldiers from the 1 st to the 12 th week of basic military training

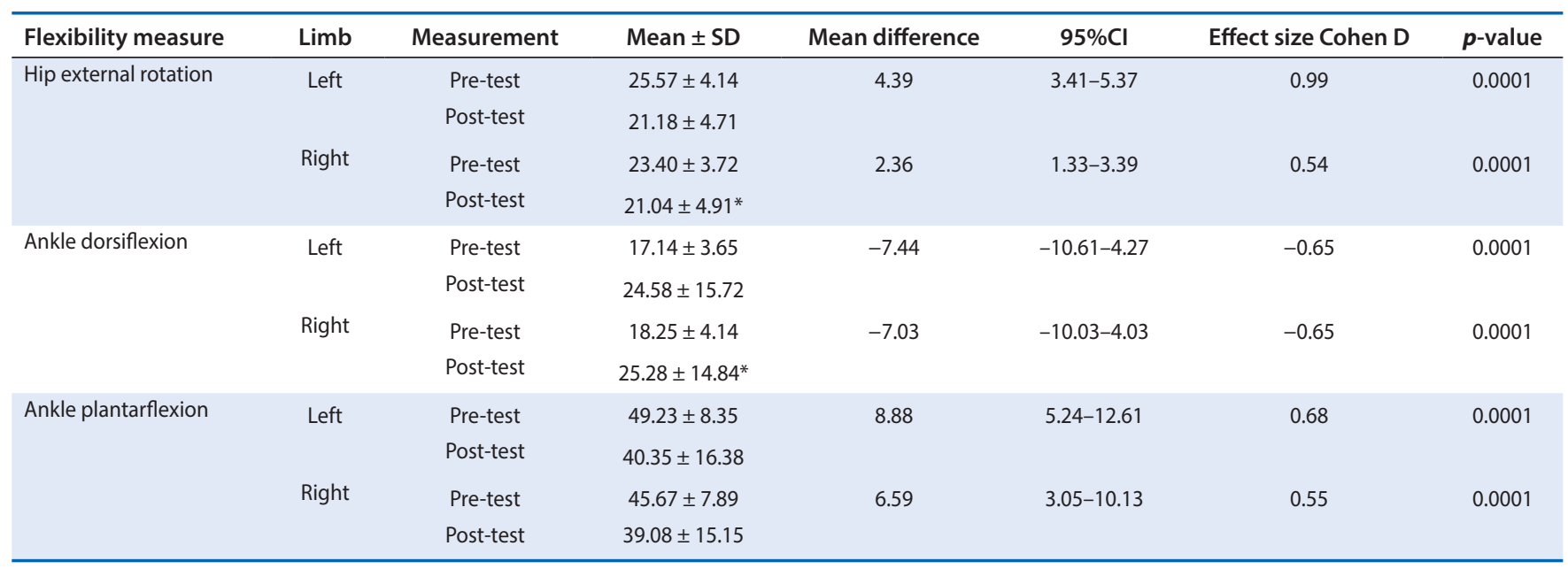


Table 6: Type and number of operational military training injuries reported during the 12 weeks of BMT

\begin{tabular}{lc}
\hline $\begin{array}{l}\text { Type of operational training } \\
\text { injury }\end{array}$ & $\begin{array}{c}\text { Number of different types of } \\
\text { operational training injuries ( } \\
\text { = 100) }\end{array}$ \\
\hline $\begin{array}{l}\text { Arthropathies } \\
\text { Dorsopathies }\end{array}$ & 50 \\
\hline $\begin{array}{l}\text { Soft-tissue disorders } \\
\text { Signs and symptoms involving the } \\
\text { neuromuscular and musculoskeletal } \\
\text { systems }\end{array}$ & 27 \\
\hline $\begin{array}{l}\text { Injuries to the elbow and forearm } \\
\text { Injuries to the hip and thigh }\end{array}$ & 4 \\
\hline $\begin{array}{l}\text { Injuries to the knee and lower leg } \\
\text { Injuries to the ankle and foot }\end{array}$ & 1 \\
\hline $\begin{array}{l}\text { Injuries to unspecified parts of trunk, } \\
\text { limbs or body }\end{array}$ & 1 \\
\hline
\end{tabular}

A total of 337 diagnoses were made at the clinic during BMT. Of these, 100 (29.67\%) were classified as operational military training injuries. Operational injuries are represented in Table 6. Among these injuries no stress fracture incidents were reported during the 12 weeks of military training.

\section{Discussion}

Normal ankle and limited hip external flexibility does not seem to predispose male South African soldiers to develop stress fractures during BMT. This cohort's mean hip external rotation of $25.57^{\circ}$ $(\mathrm{L}) / 23.40^{\circ}(\mathrm{R})$ was below the recommended $45^{\circ}-50^{\circ}$ average $\mathrm{ROM}$ value for healthy adults. ${ }^{23}$ Soldiers with external rotation of the hip greater than $65^{\circ}$ experienced an incidence of stress fracture 1.8 times higher than that of soldiers with lower degrees of rotation $(95 \% \mathrm{Cl} 1.3,2.5){ }^{5,7}$ Milgrom et al. ${ }^{37}$ failed to relate this measurement to stress-fracture risk. The difficulty involved in assessing the role of muscle and joint flexibility in stress fractures may be related to a number of factors, including the relatively imprecise measurement methods (limited by having the same tester perform all measurements), the heterogeneity of these variables and the fact that both increased and decreased flexibility may contribute. ${ }^{2}$ The BMT resulted in a significantly large decrease in both left (17.17\%) and right (10.09\%) hip external rotation.

Hughes ${ }^{13}$ showed that restricted ankle-joint dorsiflexion (ROM $<10^{\circ}$ ) was related to an increased risk of metatarsal stress fractures. The soldiers who had a reduced range were 4.6 times more likely to develop a metatarsal stress fracture. The average ankle dorsiflexion ROM value for healthy adults is $20^{\circ} . .^{23}$ This cohort's dorsiflexion flexibility $\left(17.14^{\circ} \pm 3.65(\mathrm{~L}) / 18.25^{\circ} \pm 4.14(\mathrm{R})\right)$, although slightly lower than the norm advocated by Heyward, ${ }^{23}$ does not appear to be a risk factor. Kaufman et al. ${ }^{8}$ reported that their 407 male Navy SEAL trainees had a mean ankle dorsiflexion of $20.5^{\circ} \pm 5.5$, which was higher than the dorsiflexion results measured in the male participants of this study $(17.14 \pm 3.65$ $(\mathrm{L}) / 18.25 \pm 4.14(\mathrm{R}))$. Kaufman et al. ${ }^{8}$ classified $>18.5^{\circ}$ dorsiflexion as tight and $18.5^{\circ}-23.0^{\circ}$ dorsiflexion, with the knee bent at $90^{\circ}$, as a normal range. These authors did not suggest either range to be associated with a greater risk for the development of stress fractures. ${ }^{8}$

The methodology used to assess the ankle dorsiflexion with knee at $90^{\circ}$ flexion meant that the gastrocnemius muscle was relaxed. DiGiovanni et al. $^{38}$ showed that isolated gastrocnemius contracture, as measured by dorsiflexion and with the knee at $0^{\circ}$ flexion, assisted in the development of forefoot and/or midfoot pathology in otherwise healthy people. These findings are, however, not supported by Kaufmann et al. ${ }^{8}$ As this cohort did not have limited dorsiflexion this study cannot exclude limited ankle dorsiflexion as a possible risk factor in the development of stress fractures. BMT did, however, result in a significantly large increase in the soldiers' dorsiflexion $(43.40 \%(\mathrm{~L}) / 38.52 \%(\mathrm{R}))$ over the 12 weeks (Cohen's $D>0.5$ ), possibly offering some form of protection from injury. In the South African context, further study that would entail measuring ankle dorsiflexion with the knee at $0^{\circ}$ flexion is recommended.

The increase in dorsiflexion was counteracted by a significantly large decrease in the soldiers' plantar flexion $(18.04 \%$ $(\mathrm{L}) / 14.43 \%(\mathrm{R}))$. Although studies have reported prospective flexibility measures of toe-touching ability to have increased during BMT, there appears to be no clinical relevance..$^{30,31,39,40}$ Studies have shown that lower extremity stretching before training does not offer a protective effect from stress fractures or reactions. ${ }^{40,41}$ Additionally, studies involving stretching have concluded that pre-exercise stretching did not reduce the incidence of muscle soreness or lower extremity injuries, including stress fractures, in young active adults involved in running and marching..$^{42,43}$

The PT programme followed by this cohort as outlined in Tables 2-4 does not favour a higher probability of stress fractures as it appears to have allowed sufficient periods for recovery and gradual progression of exercise intensity and duration. The PT programme also allowed for stretching at the end of each session. Regardless of the reasons, the results of this study raise questions concerning the efficacy and the necessity of pre- and post-exercise stretching for the prevention of lower extremity injuries, including stress fractures.

\section{Conclusion}

The initial flexibility of this cohort did not appear to place it at risk for the development of stress fractures; however, this study cannot exclude limited hip and ankle ROM as an intrinsic risk factor in the development of stress fractures. This study supports others that have failed to find an association between hip and ankle flexibility as a risk factor for stress-fracture development. ${ }^{8,37}$ Further studies utilising larger cohorts should be undertaken. This study highlights the need to realign the PT programme used during military training to ensure that external hip ROM and plantar flexion are at least maintained during military training, thereby possibly preventing associated injuries.

Acknowledgements - The researchers wish to thank all the military soldiers who participated and acknowledge the invaluable input and time of statistician Christine Smit and language editor Barbara English.

\section{References}

1. American College of Sports Medicine. ACSM's guidelines for exercise testing and prescription. 9th ed. Philadelphia, PA: Lippincott Williams \&Wilkins; 2014. p. 480.

2. Brukner PD, Bennell KL, Matheson G. Stress fractures. Carlton Victoria: Blackwell Science; 1999. p. 190.

3. Lacroix H, Keeman JN. An unusual stress fracture of the fibula in a long distance runner. Arch Orthop Trauma Surg. 2010;111(5):289-90.

4. Milgrom C, Giladi M, Stein M, et al. Stress fractures in military recruits: a prospective study showing an unusually high incidence. J Bone Joint Surg Am. 1985;67(5):732-5.

5. Giladi M, Milgrom C, Simkin A, et al. Stress fractures and tibial bone width: a risk factor. J Bone Joint Surg Am. 1987;69(2):326-9.

6. Montgomery LC, Nelson FR, Norton JP, et al. Orthopedic history and examination in the etiology of overuse injuries. Med Sci Sports Exerc. 1989;21(3):237-43. 
7. Giladi M, Milgrom C, Simkin A, et al. Stress fractures: identifiable risk factors. Am J Sports Med. 1991;19(6):647-52. http://dx.doi. org/10.1177/036354659101900617

8. Kaufman KR, Brodine SK, Shaffer RA, et al. The effect of foot structure and range of motion on musculoskeletal overuse injuries. Am J Sports Med. 1999;27(5):585-93.

9. Finestone A, Shlamkovitch N, Eldad A, et al. Risk factors for stress fractures among Israeli infantry recruits. Mil Med. 1991;156(10): 528-30.

10. Milgrom C, Finestone A, Shlamkovitch N, et al. Youth is a risk factor for stress fracture: a study of 783 infantry recruits. J Bone Joint Surg Am. 1999;76(1):20-2.

11. Cosman F, Ruffing J, Zion $M$, et al. Determinants of stress fracture risk in United States Military Academy cadets. Bone. 2013;55(2):359-66. http://dx.doi.org/10.1016/j.bone.2013.04.011

12. Matheson GO, Clement DB, Mckenzie DC, et al. Stress fractures in athletes: a study of 320 cases. Am J Sports Med. 1987;15(1):46-58. http://dx.doi.org/10.1177/036354658701500107

13. Hughes AW. Avulsion fracture involving the body of the patella. $\mathrm{Br}$ J Sports Med. 1985;19(2):119-20. http://dx.doi.org/10.1136/bjsm. 19.2.119

14. Brudvig TJ, Gudger TD, Obermeyer L. Stress fractures in 295 trainees: a one-year study of incidence as related to age, sex, and race. Mil Med. 1983;148(8):666-7.

15. Barrow GW, Saha S. Menstrual irregularity and stress fractures in collegiate female distance runners. Am J Sports Med. 1988;16(3):20916. http://dx.doi.org/10.1177/036354658801600302

16. Gardner LIJ, Dziados JE, Jones BH, et al. Prevention of lower extremity stress fractures: a controlled trial of a shock absorbent insole. Am J Public Health. 1988;78(12):1563-7. http://dx.doi.org/10.2105/ AJPH.78.12.1563

17. Friedl KE, Nuovo JA, Patience $T H$, et al. Factors associated with stress fracture in young army women: indications for further research. Mil Med. 1992;157(7):334-8.

18. Shaffer RA, Brodine SK, Ito SI, et al. Epidemiology of illness and injury among US navy and marine corps female training populations. Mi Med. 1999;164(1):17-21.

19. Shaffer RA, Rauh MJ, Brodine SK, et al. Predictors of stress fracture susceptibility in young female recruits. Am J Sports Med. 2006;34(1):108-15.

20. Thomas JR, Nelson JK, Silverman SJ. Research methods in physical activity. 6th ed. Champaign, IL: Human Kinetics; 2011. p. 457.

21. Chemaly CT, Macintyre UE, Abrahamse H. Calcium intake and knowledge among white adolescent girls in Gauteng, South Africa. South Afr J Clin Nutr. 2004;17(3):102-8.

22. Bierma-Zeinstra SM, Bohnen AM, Ramlal R, et al. Comparison between two devices for measuring hip joint motions. Clin Rehabil. 1998;12(6):497-505. http://dx.doi.org/10.1191/02692159867745 9668

23. Heyward V. Advanced fitness assessment and exercise prescription. 6th ed. Champaign, IL: Human Kinetics; 2010. p. 425.

24. Bennell KL, Malcolm SA, Thomas SA, et al. The incidence and distribution of stress fractures in competitive track and field athletes: a twelve-month prospective study. Am J Sports Med. 1996;24(2):211-7. http://dx.doi.org/10.1177/036354659602400217
25. Maquirriain J, Ghisi JP. The incidence and distribution of stress fractures in elite tennis players. Br J Sports Med. 2006;40(5):454-9. http://dx.doi. org/10.1136/bjsm.2005.023465

26. Department of Defence Policy on Physical Training, Department of Defence Instruction, South Africa: Surgeon General No. 00006/2000.

27. Scully TJ, Besterman G. Stress fracture - a preventable training injury. Mil Med. 1982;147(4):285-7.

28. Heir T, Eide G. Injury proneness in infantry conscripts undergoing a physical training programme: smokeless tobacco use, higher age, and low levels of physical fitness are risk factors. Scand J Med Sci Sports. 1997;7(5):304-11

29. Rudzki SJ, Cunningham MJ. The effect of a modified physical training program in reducing injury and medical discharge rates in Australian army recruits. Mil Med. 1999;164(9):648-52.

30. Kaufman KR, Brodine S, Shaffer R. Military training-related injuries: surveillance, research, and prevention. Am J Prev Med. 2000;18(1):5463. http://dx.doi.org/10.1016/S0749-3797(00)00114-8

31. Popovich RM, Gardner JW, Potter R, et al. Effect of rest from running on overuse injuries in army basic training. Am J Prev Med. 2000;18(1):14755. http://dx.doi.org/10.1016/S0749-3797(99)00167-1

32. Armstrong DW, Rue JPH, Wilckens $\mathrm{JH}$, et al. Stress fracture injury in young military men and women. Bone. 2004;35(3):806-16. http:// dx.doi.org/10.1016/j.bone.2004.05.014

33. Knapik JJ, Bullock SH, Canada S, et al. Influence of an injury reduction program on injury and fitness outcomes among soldiers. Inj Prev. 2004;10(1):37-42. http://dx.doi.org/10.1136/ip.2003.002808

34. Protzman RR. Physiologic performance of women compared to men: observationsofcadetsattheUnited States MilitaryAcademy.AmJSports Med. 1979;7(3):191-4. http://dx.doi.org/10.1177/0363546579007 00311

35. Greaney RB, Gerber FH, Laughlin RL, et al. Distribution and natural history of stress fractures in U.S. Marine recruits. Radiology. 1983; 146(2):339-46. http://dx.doi.org/10.1148/radiology.146.2.6217486

36. Cohen J. A power primer. Psychol Bull. 1992;112(1):155-9. http:// dx.doi.org/10.1037/0033-2909.112.1.155

37. Milgrom C, Finestone A, Novack V, et al. The effect of prophylactic treatment with risedronate on stress fracture incidence among infantry recruits. Bone. 2004;35(2):418-24. http://dx.doi.org/10.1016/j. bone.2004.04.016

38. DiGiovanni CW, Kuo R, Tejwani N; et al. Isolated gastrocnemius tightness. J Bone Joint Surg Am. 2002;84-A (6):962-70.

39. Jones BH, Shaffer RA, Snedecor MR. Injuries treated in outpatient clinics: surveys' and research data. Mil Med. 1999;164(Suppl 8):1-89.

40. Pope RP, Herbert RD, Kirwan JD, et al. A randomized trial of preexercise stretching for prevention of lower-limb injury. Med Sci Sports Exerc. 2000;32(2):271-7. http://dx.doi.org/10.1097/00005768-200002000-00 004

41. Shaffer SW, Uhl TL. Preventing and treating lower extremity stress reactions and fractures in adults. J Athl Train. 2006;41(4):466-9.

42. Yeung EW, Yeung SS. A systematic review of interventions to prevent lower limb soft tissue running injuries. Br J Sports Med. 2001;35(6): 383-9. http://dx.doi.org/10.1136/bjsm.35.6.383

43. Herbert RD, Gabriel M. Effects of stretching before and after exercising on muscle soreness and risk of injury: systematic review. BMJ. 2002;325(7362):468-70. http://dx.doi.org/10.1136/bmj.325.7362.468 